\title{
LA INSERCIÓN LABORAL DE GRADUADOS Y GRADUADAS A TRAVÉS DE LOS CONTACTOS PERSONALES. UNA PROPUESTA DESDE LA GESTIÓN DEL CONOCIMIENTO
}

\author{
Graduate's labour insertion through personal contacts. \\ A proposal from the knowledge management
}

Carolina FERNÁNDEZ-SALINERO DE MIGUEL* y Jesús GARCÍA-ÁLVAREZ*** *Universidad Complutense de Madrid. España.

cfernand@ucm.es

https://orcid.org/0163-1893-3478-9049

**Universidade de Santiago de Compostela. España.

jesus.garcia.alvarez@usc.es

https://orcid.org/0163-1893-4818-9060

Fecha de recepción: 20/02/2019

Fecha de aceptación: 02/07/2019

Fecha de publicación en línea: 30/10/2019

RESUMEN

La transformación de la economía a partir de la crisis financiera, junto con la aparición de nuevos productos y servicios, han supuesto un desafío, tanto en clave educativa como profesional, en la inserción laboral de las y los graduados universitarios, obligando a la educación superior a tomar decisiones en sintonía con esos cambios. En este contexto, el presente trabajo pretende ofrecer una visión analítica sobre el fenómeno de la inserción laboral a través del recurso de los contactos personales. Adoptando como hipótesis la derivada devaluación de la formación de las y los egresados en beneficio de lo que se ha denominado capital interpersonal, es decir, el volumen de redes y contactos de las y los egresados que les permiten acceder a un empleo, se proponen una serie de líneas estratégicas a desarrollar en el ámbito de la educación superior que giran en torno a la gestión de conocimiento. 
Para ello, se ha procedido con una metodología de corte cualitativo basada en la revisión sistemática de los principales estudios e informes realizados en el contexto español por universidades, observatorios de empleo, organizaciones público-privadas, agencias de evaluación de la calidad del sistema universitario y especialistas en el ámbito. Concretamente, se han analizado 56 estudios e informes realizados entre los años 2000 y 2018. Los resultados permiten identificar dos trayectorias fundamentales en la inserción laboral de los titulados superiores, descubriéndose un incremento notable en el uso del capital social como recurso de intermediación laboral en el último período analizado (2011-2018). Por consiguiente, se observa un importante cambio en la valoración de la formación de los recién titulados por parte de los propios egresados y egresadas, las y los empleadores y la universidad, justificando la propuesta planteada en relación con la gestión del conocimiento y su contribución a la empleabilidad de las y los universitarios.

Palabras clave: gestión del conocimiento; inserción laboral; formación; graduados/as; educación superior; contactos personales.

\section{ABSTRACT}

The transformation of the economy after the financial crisis, together with the appearance of new products and services, have been a challenge, both in educationally and professionally key, in the labour insertion of university graduates, requiring higher education to make decisions in synchronicity with these changes. In this context, the present paper aims to offer an analytic vision about the labour insertion phenomenon through the personal contacts' resource. Adopting as hypothesis the derived devaluation of the graduate's training in benefit of what we have called interpersonal capital, namely, the volume of graduate's networks and contacts that allow them to have access to a job, we propose a series of strategic lines to develop in the higher education field that revolve around knowledge management. To this, we situated ourselves in a qualitative methodology based on the systematic review of the principal studies and reports written in Spain by universities, employment observatories, public and private organizations, quality assessment agencies in the university system and experts in this scope. Specifically, we have analyzed 56 studies and reports carried out between the years 2000 and 2018. The results allow us to identify two fundamental trajectories in the labour insertion of graduates, finding a remarkable growth in the use of social capital as a resource of labour intermediation in the last period analyzed (2011-2018). Therefore, there is an important change in the view of recent graduates, employers and university have about their own training, justifying the propose we made in relation to knowledge management and its contribution to the employability of university students.

Keywords: knowledge management; labour insertion; training; graduates; higher education; network. 

PERSONALES. UNA PROPUESTA DESDE LA GESTIÓN DEL CONOCIMIENTO

\section{INTRODUCCIÓN}

En décadas pasadas y, hasta la llegada de la crisis financiera, datada en el año 2008 (Fondo Monetario Internacional, 2016), el «valor de un individuo» en el mundo laboral dependía fundamentalmente de su formación académica o capital institucional, el cual funcionaba como un exponente susceptible de evaluación por parte del mercado de trabajo (Carrascosa y Molero, 2010). Actualmente, el capital institucional está dejando paso al capital interpersonal o conjunto de contactos que un individuo establece para hacer operativa su entrada en el mercado de trabajo y su acceso a empleos atractivos (Boden y Nedeva, 2010; Michavila, Martínez, MartínGonzález, García-Peñalvo, y Cruz-Benito, 2016; Subires y Olmedo, 2013), lo que sin duda está provocando una tensión entre el discurso «meritocrático» y la realidad laboral (Weller, 2007).

Esto requiere definir con claridad qué se entiende por contactos personales al constituirse como un recurso de intermediación laboral que poco a poco va adquiriendo mayor protagonismo. Así, dependiendo del contexto en el que se localice el término "contacto", se alude a: (1) referencia en una empresa que nos facilita la entrada porque nos conoce y confía en nuestra valía; (2) «enchufe» o recomendación en una empresa que nos facilita la entrada porque nos conoce sin importar nuestra valía, o; (3) informante que nos advierte sobre una oferta de empleo sin participar en la relación demandante-empleador.

Todo ello, ha llevado a rescatar de la sociología de Bourdieu el concepto de capital, entendido como el instrumento de apropiación de las oportunidades teóricamente ofrecidas a todos (Bourdieu, 2000; 2007). Este es un nuevo tipo de capital intelectual (Encina, 2008; Ramezan, 2011; Ramírez, Santos, y Tejada, 2011), que unido al capital humano, estructural y relacional (activos de conocimiento según Davenport y Prusak, 1998), enriquece y amplía los elementos substanciales de la gestión del conocimiento (Ichijo y Nonaka, 2006) y explica, en clave fundamentalmente sociológica, el actual uso del recurso de los contactos personales en detrimento de la tradicional valoración de la formación académica por parte del mercado laboral — de egresados/as y universidades—; destacando el papel de la gestión del conocimiento en el desarrollo de competencias interpersonales que contribuyan a la gestión del mentado cambio. Cuestión que también refieren Pineda, Ciraso, y Armijos (2018) al señalar que, para las y los graduados universitarios, entre los déficits más importantes de formación se encuentra el desarrollo de las competencias exigidas por el mercado de trabajo. Competencias que, según Del-Arco y Enciso (2011), deben visibilizarse dentro del Espacio Europeo de Educación Superior (EEES) a través del aumento de los vínculos entre la universidad y el mercado laboral (Jover, 2016), para ayudar, especialmente, a aquellos estudiantes de estratos sociales menos favorecidos y con mayores dificultades para incorporarse al mundo del trabajo (Rahona, 2006).

En tal coyuntura, se constata que la inserción laboral del estudiante universitario ha sido ampliamente abordada en el contexto español, principalmente con carácter 
descriptivo (Ministerio de Educación, Cultura y Deporte, 2015). A pesar de ello y, aun constituyendo una cuestión social de reconocida importancia, se observa que las investigaciones realizadas no se han detenido en el análisis de las condiciones de búsqueda y acceso al mercado laboral (De Esteban y Sancho, 2017). De igual modo y, a pesar de que las cifras de desempleo asociadas al colectivo de jóvenes universitarios continúan siendo elevadas (según los últimos datos del INE-2018 la tasa de paro de jóvenes con estudios universitarios de entre 20 y 29 años alcanza el 19\%), tampoco se encuentran trabajos que, cuando menos de forma explícita, hayan diseñado propuestas que vinculen la universidad con el mundo de la empresa. Como respuesta a tal problemática, la contribución que se presenta tiene como principal objetivo realizar una revisión sistemática, focalizada en las condiciones que definen el acceso de las y los titulados universitarios al mercado de trabajo, para justificar el diseño de una serie de estratégicas de potencial empleabilidad centradas en la gestión del conocimiento como propuesta de cambio.

En este contexto, se descubre una diversidad terminológica que obliga a distinguir entre varios conceptos, próximos entre sí. De manera específica, es necesario hacer una diferenciación entre inserción laboral, empleabilidad y emprendimiento. Sin querer ser exhaustivos en la conceptualización de estos términos, cuando se habla del proceso de inserción laboral se hace referencia a las condiciones de búsqueda y acceso al empleo, con carácter general, donde juegan un importante papel las condiciones de entrada al propio mercado de trabajo, es decir, los factores de «Ocupabilidad» (García-Blanco y Cárdenas-Sempértegui, 2018). Por su parte, la empleabilidad supone la transición al mundo del trabajo desde el punto de vista particular del sujeto que accede a una ocupación, en otras palabras, hace referencia a su competencia para emplearse e integrarse en el mercado laboral (García-Gutiérrez, 2014). Por último, el emprendimiento, con frecuencia utilizado como eufemismo del autoempleo, implica aquellas habilidades y destrezas que le permiten al sujeto poner en marcha iniciativas, diseñar nuevos proyectos y/o generar ideas innovadoras (Fernández-Salinero y De la Riva, 2014).

Tras esta delimitación conceptual, breve pero precisa, y al centrarse el objetivo de este trabajo en realizar una revisión sistemática de los estudios llevados a cabo en el contexto español sobre el acceso al empleo de las y los graduados universitarios, lo más conveniente es referirse a tal proceso desde una perspectiva general e integradora, es decir, aquella que es posible abordar desde el concepto de inserción laboral, íntimamente ligado no obstante a los de empleabilidad y emprendimiento, al exigirse mutuamente.

Se ha analizado la literatura científica de mayor impacto en esta área, así como aquellas investigaciones, nacionales y autonómicas, de carácter cuantitativo centradas en el uso de los contactos personales y en la formación para el empleo. Este tema es de suma actualidad, no solo en España, sino más allá de nuestras fronteras, lo que se deduce de las investigaciones llevadas a cabo a nivel internacional y que 
sirven de apoyo para el presente trabajo. A este respecto, en Estados Unidos se lleva trabajando en estos temas con gran intensidad desde los años 80, como se puede comprobar a partir de los informes elaborados por la "National Association of Colleges and Employers (NACE)» (Cabrera, Weerts, y Zulick, 2003). Por su parte, en la Unión Europea cabe destacar el estudio "Careers after Higher Education: a Euroepan Research Survey (CHEERS)», desarrollado a finales de los años 90 (Teichler, 2003), así como el proyecto «Research on the Flexible Professional in the Knowledge Society (REFLEX)» (Carot, Conchado, Mora, y Vila, 2011) y el proyecto "Profesional Flexible en la Sociedad del Conocimiento (PROFLEX)», que une Europa y Latinoamérica (Mora, Carot, y Conchado, 2010). Todos ellos analizan el papel de la universidad en la formación para el empleo de sus estudiantes y las competencias que estos y estas ponen en juego para mejorar su inserción laboral y responder a los requerimientos del mercado de trabajo.

\section{OBJETIVO DE LA INVESTIGACIÓN}

Para desarrollar este trabajo se establece como objetivo realizar una revisión sistemática a partir de un conjunto de investigaciones sobre inserción laboral, focalizada en las condiciones que definen el acceso de las y los titulados universitarios españoles al mercado de trabajo para justificar el diseño de una serie de estratégicas de potencial empleabilidad centradas en la gestión del conocimiento como propuesta de cambio.

\section{Propuesta metodológica}

El presente estudio se apoya en lo que Bisquerra (2009) denominada «teoría fundamentada", un método cualitativo de investigación de naturaleza exploratoria, cuyo propósito es descubrir conceptos y proposiciones partiendo directamente de los datos, realizando para ello un análisis descriptivo-interpretativo, ya que lo que se pretende es la identificación y categorización de elementos y la exploración de sus conexiones.

Se realiza con este fin una selección de investigaciones, identificando como noción rectora el concepto de capital. No obstante, ha de considerarse que la literatura científica, a la hora de medir dicho capital, utiliza variables como: competencias interpersonales, contactos personales, redes sociales o red de contactos, entre otras. Por lo tanto, reteniendo esta herramienta conceptual, se ha optado por denominar capital interpersonal a las competencias socio-relacionales como útil de operatividad. Asimismo, se han examinado artículos y monografías relacionadas con la sociología de Bourdieu, así como otros más pedagógicos (DuBrin, 1997; García, 2016; García-Valdecasas, 2014; Neira, Portela, Cancelo, y Calvo, 2013), con la finalidad de determinar qué conceptos clave pueden modular la selección de las investigaciones. 
En este sentido, a través de una precisa revisión documental sistemática y planificada, entendida como la integración estructurada y ordenada de la información obtenida en diferentes estudios sobre un problema determinado, se ha efectuado un análisis de las principales investigaciones sobre inserción laboral de los graduados y las graduadas en España. Para ello, se han utilizado las bases de datos Science Direct, Web of Science, Google Scholar y SCOPUS. No obstante, con frecuencia los estudios sobre inserción laboral de graduados y graduadas son efectuados por las propias universidades y agencias para la calidad del sistema universitario, por lo que también han sido incluidas dichas instituciones en nuestra búsqueda.

Los artículos fueron seleccionados utilizando las palabras clave «empleabilidad», "inserción laboral", "acceso al empleo", "transición a la vida activa", "graduados y graduadas», "titulados y tituladas superiores» y «universitarios y universitarias». Para registrar los datos se empleó un protocolo que facilitaba la organización y estructuración de la información en los siguientes campos: año de publicación, autor/ es, metodología utilizada, lugar donde se realizó el estudio, descripción de los participantes y objetivos.

Al mismo tiempo y, a fin de realizar una selección lo más ajustada posible al objetivo inicialmente planteado, se han definido cuatro criterios que debían cumplir los estudios e investigaciones. Bajo esta premisa, fueron seleccionados un total de 56 documentos, los cuales respetaban los cuatro criterios establecidos:

- Que una de las variables analizadas fuera las vías de acceso al empleo que, a pesar de ser una de las más discutidas en el contexto de los estudios de inserción, por cuanto no discrimina adecuadamente entre "conocimiento de la oferta» y "acceso real al trabajo», resulta la más oportuna al identificarse con similar denominación en los estudios analizados. Selección que, no obstante, no permite discriminar completamente los tres tipos de contactos personales definidos previamente en la investigación.

- Que se especificase el instrumento empleado para la recogida de información.

- Que la población estuviera formada por graduados y graduadas superiores de distintas titulaciones impartidas en universidades españolas, sin establecer diferencias por ramas de conocimiento.

- Que se garantizase la representatividad de la muestra a través de indicadores que otorgasen validez y fiabilidad a los datos obtenidos.

A este respecto, se incluyeron estudios que hiciesen visible el proceso de inserción laboral de las y los graduados del conjunto de las Comunidades Autónomas. Unos elaborados por universidades y otros por agencias de evaluación de la calidad del sistema universitario de cada territorio. Por su parte, en aquellas comunidades donde no se ha constatado un seguimiento de los procesos de inserción laboral 
de sus egresados y egresadas por parte de universidades o agencias de calidad, se han analizado estudios procedentes de observatorios de empleo, de organizaciones público-privadas, de especialistas en el ámbito o del Instituto Nacional de Estadística (INE, 2010; 2016). Todos ellos caracterizados por emplear el cuestionario o la encuesta como principal instrumento de recogida de datos, siendo planteada la variable "vías de acceso al empleo» en una sola pregunta, cerrada y con opciones específicas de respuesta.

\section{FORMACIÓN Y TRANSICIÓN AL EMPLEO DE LAS Y LOS GRADUADOS UNIVERSITARIOS}

Una vez identificados los estudios, se han establecido dos períodos de análisis: 2000-2010 y 2011-2018 (véase Tabla 1). Esta diferenciación se ha hecho porque, a pesar de que el Fondo Monetario Internacional sitúa el comienzo de la crisis económica en el año 2008, período que coincide con el cambio en el uso de los recursos de acceso al empleo, se han encontrado estudios de los años 2009 y 2010 referidos a promociones que se titularon durante el año 2008 y anteriores, por lo que se ha considerado oportuno ubicar el punto de inflexión en el año 2010 para finalizar el primer período y en el año 2011 para iniciar el segundo.

\section{TABLA 1}

Revisión de estudios e informes sobre el acceso al empleo de graduados y graduadas

\begin{tabular}{|c|c|}
\hline PERÍODO 2000-2010 & PERÍODO 2011-2018 \\
\hline \multicolumn{2}{|c|}{ ANDALUCÍA } \\
\hline $\begin{array}{l}\text { Valero (2003). } \\
\text { Instrumento: cuestionario. } \\
\mathrm{n}=689 \text {. } \\
\text { Vía de acceso al empleo: bolsa de prácticas } \\
(45 \%) .\end{array}$ & $\begin{array}{l}\text { Valero (2012). } \\
\text { Instrumento: cuestionario. } \\
\mathrm{n}=490 . \\
\text { Vía de acceso al empleo: red de contactos } \\
\text { (16,5\%). Distribución residual del resto de } \\
\text { porcentajes. }\end{array}$ \\
\hline $\begin{array}{l}\text { Universidad de Jaén (2008). } \\
\text { Instrumento: encuesta. } \\
\mathrm{n}=1005 \text {. } \\
\text { Vía de acceso al empleo: envío del } \\
\text { currículum (28,19\%). Distribución residual del } \\
\text { resto de porcentajes. }\end{array}$ & $\begin{array}{l}\text { Universidad de Jaén (2012). } \\
\text { Instrumento: encuesta. } \\
\mathrm{n}=1723 \text {. } \\
\text { Vía de acceso al empleo: amigos, familiares } \\
\text { y conocidos }(36,09 \%) \text {. }\end{array}$ \\
\hline $\begin{array}{l}\text { Universidad de Cádiz (2005). } \\
\text { Instrumento: encuesta. } \\
\mathrm{n}=1542 \text {. } \\
\text { Vía de acceso al empleo: envío del } \\
\text { currículum }(54,8 \%) \text {. }\end{array}$ & $\begin{array}{l}\text { INE (2016). Datos desagregados Andalucía. } \\
\text { Instrumento: encuesta. } \\
\mathrm{n}=45980 . \\
\text { Vía de acceso al empleo: contactos } \\
\text { personales }(25,1 \%) \text {. Distribución residual } \\
\text { del resto de porcentajes. }\end{array}$ \\
\hline
\end{tabular}




\begin{tabular}{|c|c|}
\hline PERÍODO 2000-2010 & PERÍODO 2011-2018 \\
\hline \multicolumn{2}{|c|}{ ASTURIAS } \\
\hline $\begin{array}{l}\text { Lorences (2005). } \\
\text { Instrumento: encuesta. } \\
\mathrm{n}=3138 \text {. } \\
\text { Vía de acceso al empleo: envío del } \\
\text { currículum (27,8\%). Distribución residual del } \\
\text { resto de porcentajes. }\end{array}$ & $\begin{array}{l}\text { INE (2016). Datos desagregados Asturias. } \\
\text { Instrumento: encuesta. } \\
\mathrm{n}=5531 . \\
\text { Vía de acceso al empleo: contactos } \\
\text { personales }(20,7 \%) \text {. Distribución residual } \\
\text { del resto de porcentajes. }\end{array}$ \\
\hline \multicolumn{2}{|c|}{ ARAGÓN } \\
\hline $\begin{array}{l}\text { Observatorio de Empleo de la Universidad } \\
\text { de Zaragoza (2006). } \\
\text { Instrumento: encuesta. } \\
\mathrm{n}=1796 . \\
\text { Vía de acceso al empleo: otros }(24,05 \%) \text { y } \\
\text { medios de comunicación }(19,56 \%) \text {. }\end{array}$ & $\begin{array}{l}\text { González-Santos, Ratia, y Yagüe (2011). } \\
\text { Instrumento: encuesta. } \\
\text { n=1675. } \\
\text { Vía de acceso al empleo: contactos } \\
\text { personales (25\%). Distribución residual del } \\
\text { resto de porcentajes. }\end{array}$ \\
\hline \multicolumn{2}{|c|}{ CANTABRIA } \\
\hline $\begin{array}{l}\text { INE (2010). Datos desagregados Cantabria. } \\
\text { Instrumento: encuesta. } \\
\mathrm{n}=2619 \text {. } \\
\text { Vía de acceso al empleo: anuncios en } \\
\text { prensa y/o internet (19,2\%). Distribución } \\
\text { residual del resto de porcentajes. }\end{array}$ & $\begin{array}{l}\text { Universidad de Cantabria (2015). } \\
\text { Instrumento: encuesta. } \\
\mathrm{n}=57 . \\
\text { Vía de acceso al empleo: contactos } \\
\text { personales }(30,2 \%) \text {. }\end{array}$ \\
\hline \multicolumn{2}{|c|}{ CASTILLA LA MANCHA } \\
\hline $\begin{array}{l}\text { Universidad de Castilla La Mancha (2005). } \\
\text { Instrumento: encuesta. } \\
\mathrm{n}=4699 \text {. } \\
\text { Vía de acceso al empleo: envío del } \\
\text { currículum }(38,02 \%) \text {. }\end{array}$ & $\begin{array}{l}\text { INE (2016). Datos desagregados Castilla La } \\
\text { Mancha. } \\
\text { Instrumento: encuesta. } \\
\mathrm{n}=6905 . \\
\text { Vía de acceso al empleo: contactos } \\
\text { personales (20,3\%). Distribución residual } \\
\text { del resto de porcentajes. }\end{array}$ \\
\hline \multicolumn{2}{|c|}{ CASTILLA Y LEÓN } \\
\hline $\begin{array}{l}\text { Vidal, López, Pérez, y Vieira (2001). } \\
\text { Instrumento: cuestionario. } \\
\text { n=390. } \\
\text { Vía de acceso al empleo: anuncios en } \\
\text { prensa (44,36\%) y agencia pública de } \\
\text { empleo (40\%). }\end{array}$ & $\begin{array}{l}\text { Boyano (2011). } \\
\text { Instrumento: encuesta. } \\
\mathrm{n}=6226 . \\
\text { Vía de acceso al empleo: relaciones } \\
\text { personales }(23,2 \%) \text {. Distribución residual } \\
\text { del resto de porcentajes. }\end{array}$ \\
\hline \multicolumn{2}{|r|}{ CATALUÑA } \\
\hline $\begin{array}{l}\text { Rodríguez (2003). } \\
\text { Instrumento: encuesta. } \\
\text { n=9766. } \\
\text { Vía de acceso al empleo: anuncios de } \\
\text { prensa ( } 21 \%) \text {. }\end{array}$ & $\begin{array}{l}\text { Agència per a la Qualitat del Sistema } \\
\text { Universitari de Catalunya (2017). } \\
\text { Instrumento: encuesta. } \\
\mathrm{n}=15563 . \\
\text { Vía de acceso al empleo: contactos } \\
\text { personales }(40,4 \%) \text {. }\end{array}$ \\
\hline
\end{tabular}


CAROLINA FERNÁNDEZ-SALINERO DE MIGUEL Y JESÚS GARCÍA-ÁLVAREZ

LA INSERCIÓN LABORAL DE GRADUADOS Y GRADUADAS A TRAVÉS DE LOS CONTACTOS

PERSONALES. UNA PROPUESTA DESDE LA GESTIÓN DEL CONOCIMIENTO

\begin{tabular}{|c|c|}
\hline PERÍODO 2000-2010 & PERÍODO 2011-2018 \\
\hline \multicolumn{2}{|c|}{ COMUNIDAD VALENCIANA } \\
\hline $\begin{array}{l}\text { Servicio Integrado de Empleo de la } \\
\text { Universidad Politécnica de Valencia (2009). } \\
\text { Instrumento: encuesta. } \\
\mathrm{n}=2131 \text {. } \\
\text { Vía de acceso al empleo: envío del currículum } \\
(52,6 \%) \text {. }\end{array}$ & $\begin{array}{l}\text { Gil (2011). } \\
\text { Instrumento: encuesta. } \\
\mathrm{n}=339 . \\
\text { Vía de acceso al empleo: contactos } \\
\text { personales y profesionales }(64,4 \%)\end{array}$ \\
\hline $\begin{array}{l}\text { García-Montalvo y Peiró (2009). } \\
\text { Instrumento: encuesta. } \\
\text { n=1200. } \\
\text { Vía de acceso al empleo: envío del } \\
\text { currículum (52\%). }\end{array}$ & $\begin{array}{l}\text { García-Montalvo y Peiró (2011). } \\
\text { Instrumento: encuesta y entrevista. } \\
\mathrm{n}=2000 . \\
\text { Vía de acceso al empleo: falta de contactos } \\
(42,1 \%) \text { como factor que dificulta encontrar } \\
\text { trabajo. }\end{array}$ \\
\hline $\begin{array}{l}\text { Observatorio Ocupacional de la Universitat } \\
\text { Jaume I (2003). } \\
\text { Instrumento: encuesta. } \\
\mathrm{n}=779 \text {. } \\
\text { Vía de acceso al empleo: anuncios en } \\
\text { prensa }(50 \%) \text { y agencia de colocación } \\
\text { pública }(48 \%) \text {. }\end{array}$ & $\begin{array}{l}\text { Cantero (2012). } \\
\text { Instrumento: cuestionario. } \\
\mathrm{n}=339 . \\
\text { Vía de acceso al empleo: contactos } \\
\text { personales (30\%). }\end{array}$ \\
\hline \multicolumn{2}{|c|}{ EXTREMADURA } \\
\hline $\begin{array}{l}\text { Trinidad, Villalobos, Martín, y Panduro } \\
\text { (2009). } \\
\text { Instrumento: entrevista. } \\
\text { n=1357. } \\
\text { Vía de acceso al empleo: envío del } \\
\text { currículum (26,1\%). Distribución residual del } \\
\text { resto de porcentajes. }\end{array}$ & $\begin{array}{l}\text { Villalobos, Trinidad, Díaz y Chamorro } \\
\text { (2014). } \\
\text { Instrumento: encuesta. } \\
\text { n=2395. } \\
\text { Vía de acceso al empleo: contactos personales } \\
\text { o familiares (27,8\%). Distribución residual del } \\
\text { resto de porcentajes. }\end{array}$ \\
\hline $\begin{array}{l}\text { Pérez, Vicente, y Cubo (2008). } \\
\text { Instrumento: cuestionario. } \\
\mathrm{n}=313 \text {. } \\
\text { Vía de acceso al empleo: envío del } \\
\text { currículum }(73,8 \%) \text {, inscripción en el } \\
\text { Servicio Extremeño Público de Empleo } \\
(59,1 \%) \text { e internet }(44,7 \%) \text {. }\end{array}$ & $\begin{array}{l}\text { INE (2016). Datos desagregados } \\
\text { Extremadura. } \\
\text { Instrumento: encuesta. } \\
\mathrm{n}=5705 . \\
\text { Vía de acceso al empleo: contactos } \\
\text { personales }(21,7 \%) \text {. Distribución residual } \\
\text { del resto de porcentajes. }\end{array}$ \\
\hline \multicolumn{2}{|c|}{ GALICIA } \\
\hline $\begin{array}{l}\text { Axencia para a Calidade do Sistema } \\
\text { Universitario de Galicia (2004). } \\
\text { Instrumento: encuesta. } \\
\mathrm{n}=5293 \text {. } \\
\text { Vía de acceso al empleo: cartas de solicitud } \\
\text { de entrevista }(62,4 \%) \text { y responder a } \\
\text { anuncios }(59,6 \%) .\end{array}$ & $\begin{array}{l}\text { Axencia para a Calidade do Sistema } \\
\text { Universitario de Galicia (2016). } \\
\text { Instrumento: encuesta. } \\
\mathrm{n}=4687 . \\
\text { Vía de acceso al empleo: contactos } \\
\text { personales (19,14\%). Distribución residual } \\
\text { del resto de porcentajes. }\end{array}$ \\
\hline
\end{tabular}




\begin{tabular}{|c|c|}
\hline PERÍODO 2000-2010 & PERÍODO 2011-2018 \\
\hline \multicolumn{2}{|r|}{ GALICIA } \\
\hline $\begin{array}{l}\text { Freire (2009). } \\
\text { Instrumento: cuestionario. } \\
\mathrm{n}=1516 \text {. } \\
\text { Vía de acceso al empleo: envío del } \\
\text { currículum }(30,12 \%) \text {. }\end{array}$ & $\begin{array}{l}\text { Freire (2012). } \\
\text { Instrumento: cuestionario. } \\
\mathrm{n}=1750 . \\
\text { Vía de acceso al empleo: redes informales } \\
(28,96 \%) \text {. Distribución residual del resto de } \\
\text { porcentajes. }\end{array}$ \\
\hline \multicolumn{2}{|c|}{ ISLAS BALEARES } \\
\hline $\begin{array}{l}\text { Mairata (2008). } \\
\text { Instrumento: encuesta. } \\
\mathrm{n}=1301 \text {. } \\
\text { Vía de acceso al empleo: autocandidatura } \\
\text { (61\%). }\end{array}$ & $\begin{array}{l}\text { INE (2016). Datos desagregados Islas } \\
\text { Baleares. } \\
\text { Instrumento: encuesta. } \\
\mathrm{n}=2757 . \\
\text { Vía de acceso al empleo: contactos } \\
\text { personales (28\%). Distribución residual del } \\
\text { resto de porcentajes. }\end{array}$ \\
\hline \multicolumn{2}{|c|}{ ISLAS CANARIAS } \\
\hline $\begin{array}{l}\text { Cardenal (2010). } \\
\text { Instrumento: encuesta. } \\
\text { n=912. } \\
\text { Vía de acceso al empleo: internet, envío } \\
\text { del currículum y prensa escrita (porcentajes } \\
\text { superiores al 60\%). }\end{array}$ & $\begin{array}{l}\text { INE (2016). Datos desagregados Islas } \\
\text { Canarias. } \\
\text { Instrumento: encuesta. } \\
\mathrm{n}=7078 \text {. } \\
\text { Vía de acceso al empleo: contactos } \\
\text { personales (26,5\%). Distribución residual } \\
\text { del resto de porcentajes. }\end{array}$ \\
\hline \multicolumn{2}{|r|}{ LA RIOJA } \\
\hline $\begin{array}{l}\text { Observatorio de Inserción Laboral y } \\
\text { Tendencias Profesionales Emergentes de la } \\
\text { Universidad de la Rioja (2010). } \\
\text { Instrumento: encuesta y entrevista. } \\
\mathrm{n}=285 \text {. } \\
\text { Vía de acceso al empleo: internet }(26,5 \%) \text { y } \\
\text { otros (24,3\%). }\end{array}$ & $\begin{array}{l}\text { INE (2016). Datos desagregados La Rioja. } \\
\text { Instrumento: encuesta. } \\
n=1314 . \\
\text { Vía de acceso al empleo: contacto con } \\
\text { empleadores o contactos personales } \\
\text { (23,1\%). Distribución residual del resto de } \\
\text { porcentajes. }\end{array}$ \\
\hline \multicolumn{2}{|c|}{ MADRID } \\
\hline $\begin{array}{l}\text { Universidad Politécnica de Madrid (2009). } \\
\text { Instrumento: cuestionario. } \\
\mathrm{n}=396 . \\
\text { Vía de acceso al empleo: web de empleo } \\
\text { ( } 25 \%) \text {, servicios de empleo del Centro } \\
\text { de Orientación e Información de Empleo } \\
(12 \%) \text { o Facultad (6\%). }\end{array}$ & $\begin{array}{l}\text { Universidad Politécnica de Madrid (2017). } \\
\text { Instrumento: encuesta y entrevista. } \\
\text { n=1480. } \\
\text { Vía de acceso al empleo: amigos y } \\
\text { familiares (17,80\%), contactos derivados de } \\
\text { la participación en programas de prácticas } \\
(4 \%) \text { y por intermediación de un docente } \\
(8,7 \%) \text {. Por tanto, el } 30,5 \% \text { de los titulados/ } \\
\text { as utiliza como vía de acceso al empleo } \\
\text { diferentes tipos de contactos. }\end{array}$ \\
\hline
\end{tabular}


CAROLINA FERNÁNDEZ-SALINERO DE MIGUEL Y JESÚS GARCÍA-ÁLVAREZ LA INSERCIÓN LABORAL DE GRADUADOS Y GRADUADAS A TRAVÉS DE LOS CONTACTOS PERSONALES. UNA PROPUESTA DESDE LA GESTIÓN DEL CONOCIMIENTO

\begin{tabular}{|c|c|}
\hline PERÍODO 2000-2010 & PERÍODO 2011-2018 \\
\hline \multicolumn{2}{|c|}{ MADRID } \\
\hline $\begin{array}{l}\text { Fundación Universidad Carlos III (2009). } \\
\text { Instrumento: cuestionario. } \\
\mathrm{n}=759 \text {. } \\
\text { Vía de acceso al empleo: portales } \\
\text { virtuales de empleo (24,2\%) y Servicio de } \\
\text { Orientación y Planificación Profesional } \\
(22 \%) \text {. }\end{array}$ & $\begin{array}{l}\text { Fundación Universidad Carlos III (2018). } \\
\text { Instrumento: cuestionario. } \\
\mathrm{n}=1139 \text {. } \\
\text { Vía de acceso al empleo: contactos } \\
\text { personales (16,6\%) y contactos derivados } \\
\text { de la participación en programas de } \\
\text { prácticas (34,6\%). Por tanto, el 51,2\% de los } \\
\text { titulados/as utiliza como vía de acceso al } \\
\text { empleo diferentes tipos de contactos. }\end{array}$ \\
\hline $\begin{array}{l}\text { Observatorio de Empleo de la Universidad } \\
\text { Autónoma de Madrid (2010). } \\
\text { Instrumento: encuesta. } \\
\mathrm{n}=1712 \text {. } \\
\text { Vía de acceso al empleo: Internet } \\
\text { (27,9\%). Distribución residual del resto de } \\
\text { porcentajes. }\end{array}$ & $\begin{array}{l}\text { Observatorio de Empleo de la Universidad } \\
\text { Autónoma de Madrid (2016). } \\
\text { Instrumento: encuesta. } \\
\mathrm{n}=1752 \text {. } \\
\text { Vía de acceso al empleo: contactos } \\
\text { personales }(36,2 \%) \text {. }\end{array}$ \\
\hline $\begin{array}{l}\text { Unidad de Calidad y Prospectiva de la } \\
\text { Universidad de Comillas (2007). } \\
\text { Instrumento: cuestionario. } \\
\mathrm{n}=385 \text {. } \\
\text { Vía de acceso al empleo: bolsa de trabajo } \\
\text { universitaria (22,44\%). Distribución residual } \\
\text { del resto de porcentajes. }\end{array}$ & $\begin{array}{l}\text { Unidad de Calidad y Prospectiva de la } \\
\text { Universidad de Comillas (2011). } \\
\text { Instrumento: cuestionario. } \\
\mathrm{n}=352 . \\
\text { Vía de acceso al empleo: contactos } \\
\text { personales (23,3\%). Distribución residual } \\
\text { del resto de porcentajes. }\end{array}$ \\
\hline \multicolumn{2}{|c|}{ MURCIA } \\
\hline $\begin{array}{l}\text { Osuna, Sánchez, y López (2006). } \\
\text { Instrumento: encuesta. } \\
\mathrm{n}=4077 \text {. } \\
\text { Vía de acceso al empleo: autocandidatura } \\
(38,54 \%) .\end{array}$ & $\begin{array}{l}\text { García-Palma y Martínez (2014). } \\
\text { Instrumento: encuesta. } \\
\mathrm{n}=1876 . \\
\text { Vía de acceso al empleo: contactos } \\
\text { personales }(24,4 \%) \text {. Distribución residual } \\
\text { del resto de porcentajes. }\end{array}$ \\
\hline \multicolumn{2}{|r|}{ NAVARRA } \\
\hline $\begin{array}{l}\text { Fundación Universidad-Sociedad (2010). } \\
\text { Instrumento: encuesta. } \\
\mathrm{n}=139 \text {. } \\
\text { Vía de acceso al empleo: bolsas de trabajo } \\
\text { (60\%) y foros de empleo ( } 40 \%) \text {. }\end{array}$ & $\begin{array}{l}\text { Confederación de Empresarios de Navarra } \\
(2012) \text {. } \\
\text { Instrumento: cuestionario y entrevista. } \\
n=404 . \\
\text { Vía de acceso al empleo: contactos } \\
\text { personales (18,8\%). Distribución residual } \\
\text { del resto de porcentajes. }\end{array}$ \\
\hline
\end{tabular}


CAROLINA FERNÁNDEZ-SALINERO DE MIGUEL Y JESÚS GARCÍA-ÁLVAREZ LA INSERCIÓN LABORAL DE GRADUADOS Y GRADUADAS A TRAVÉS DE LOS CONTACTOS PERSONALES. UNA PROPUESTA DESDE LA GESTIÓN DEL CONOCIMIENTO

\begin{tabular}{|c|c|}
\hline PERÍODO 2000-2010 & PERÍODO 2011-2018 \\
\hline \multicolumn{2}{|c|}{ PAÍs VASCO } \\
\hline $\begin{array}{l}\text { Observatorio del Mercado de Trabajo- } \\
\text { LANBIDE (2010). } \\
\text { Instrumento: encuesta. } \\
\mathrm{n}=5849 \text {. } \\
\text { Vía de acceso al empleo: autocandidatura } \\
\text { (24\%). Distribución residual del resto de } \\
\text { porcentajes. }\end{array}$ & $\begin{array}{l}\text { Observatorio del Mercado de Trabajo- } \\
\text { LANBIDE (2017). } \\
\text { Instrumento: encuesta. } \\
\mathrm{n}=5598 \text {. } \\
\text { Vía de acceso al empleo: contactos } \\
\text { personales (22\%). Distribución residual del } \\
\text { resto de porcentajes. }\end{array}$ \\
\hline \multicolumn{2}{|c|}{ ESPAÑA } \\
\hline $\begin{array}{l}\text { Instituto de la Mujer (2008). } \\
\text { Instrumento: cuestionario y grupo de } \\
\text { discusión. } \\
\mathrm{n}=800 \text {. } \\
\text { Vía de acceso al empleo: envío del } \\
\text { currículum ( } 48 \% \text { ). }\end{array}$ & $\begin{array}{l}\text { Michavila, et al. (2016). } \\
\text { Instrumento: encuesta. } \\
\mathrm{n}=13006 \text {. } \\
\text { Vía de acceso al empleo: contactos } \\
\text { personales }(47,9 \%)\end{array}$ \\
\hline $\begin{array}{l}\text { García-Montalvo y Ginés-Mora (2000). } \\
\text { Instrumento: encuesta y entrevista. } \\
\mathrm{n}=7257 \text {. } \\
\text { Vía de acceso al empleo: anuncios de } \\
\text { trabajo (17\%). Distribución residual del } \\
\text { resto de porcentajes. }\end{array}$ & $\begin{array}{l}\text { Pin, Apascaritei, Susaeta, y Gallifa (2013). } \\
\text { Instrumento: encuesta y grupo de } \\
\text { discusión. } \\
\mathrm{n}=255 \text {. } \\
\text { Vía de acceso al empleo: contactos } \\
\text { personales }(52 \%) \text {. }\end{array}$ \\
\hline
\end{tabular}

Fuente: Elaboración propia

Como se advierte, en las 28 investigaciones analizadas en el primer período (2000-2010) predominan como recursos de intermediación laboral: envío del currículum, anuncios en prensa, internet, autocandidatura, Servicios Públicos de Empleo y servicios de orientación. Análogamente, en las 28 investigaciones del segundo período (2011-2018) se observa la presencia del factor «contactos» como el recurso considerado más eficaz.

En relación con los recursos menos valorados, los titulados y tituladas que se encuentran en el primer período destacan las oposiciones y la red de contactos. Por el contrario, en el período que corresponde al momento actual, señalan las empresas de trabajo temporal y los servicios institucionales ofertados por la universidad. Estos datos advierten de un cambio de percepción por parte de los titulados y tituladas en todo el territorio nacional, derivado de las transformaciones económico-profesionales, que demanda una mayor implicación del contexto académico en el desarrollo de estrategias que contribuyan a mejorar la empleabilidad de las y los egresados y su adaptación a las necesidades del mercado (De Esteban y Sancho, 2017).

La literatura especializada demuestra, a este respecto y de manera consistente, que un contacto personal mejora las oportunidades de acceso a una ocupación informando al empleador de que el sujeto cuenta con las capacidades necesarias 
para el puesto (Flap y Boxman, 2000). Por tanto, los contactos personales y redes sociales juegan un rol esencial en lo que tiene que ver con la transición al empleo (Burt, 1995; Harvey, 2008).

Las redes sociales implican a distintos agentes que interactúan y se comunican recíprocamente, compartiendo recursos e información en el proceso de inserción laboral (Beech, 2015). En consecuencia y, considerando los datos analizados, es posible inferir que gestionar una red propia de contactos influirá positivamente en las decisiones de contratación. Tal coyuntura sitúa a graduados y graduadas ante una realidad que demanda propuestas coherentes que sitúen la formación universitaria a la altura de los nuevos tiempos, diseñando acciones formativas de orientación e inserción laboral que pivoten en torno a la construcción de redes y contactos que, en definitiva, suponen una contribución al capital social.

Conviene añadir, en relación a los estudios identificados, que el capital social se constituye como un factor determinante del éxito en el mercado de trabajo actual. De este modo, el uso de los contactos personales y su relevancia en el acceso al empleo, es una característica estructural del mercado laboral, que a su vez puede ayudar a estudiar otras cuestiones como su peso en el acceso a empleos cualificados y no cualificados, su incidencia sobre la configuración de expectativas de futuro, las diferencias en el acceso al ámbito público y/o privado, o su influencia en función del nivel socio-económico de origen.

No obstante, es cierto que durante el período de recesión económica el uso del capital social empieza a considerarse como un medio adecuado para gestionar la entrada en el mercado de trabajo. Ahora bien, en ese momento existen barreras estructurales que dificultan la movilización de los contactos personales, sobre todo cuando se accede a empleos cuya formalización es excesiva o cuentan con mecanismos de selección específicos, caso de algunos empleos en grandes compañías o de empleos públicos.

En este escenario, la universidad debe actuar no solo como espacio de formación especializada o como facilitadora de redes de contacto, también como capital social mediador para el empleo, de ahí que la gestión del conocimiento pueda entenderse como una propuesta de potencial empleabilidad en el ámbito de la educación superior. Y es que a pesar de que los contactos personales han tenido un crecimiento notable en la última década, como ya se ha indicado previamente, formaban parte del conjunto de vías de acceso al mercado laboral antes de la crisis económica.

Desde esta perspectiva, la revisión sistemática realizada permite proponer dos posibles trayectorias en la inserción laboral de los titulados y tituladas superiores. La primera apunta al procedimiento tradicional de búsqueda y acceso a un puesto de trabajo, donde destaca la utilización de diversos recursos. La segunda atañe a la actual vía de acceso caracterizada por el uso de los contactos personales como principal recurso de inserción profesional (ver Gráfico 1). 
GRÁFICO 1

Cambio de trayectoria en el acceso al empleo

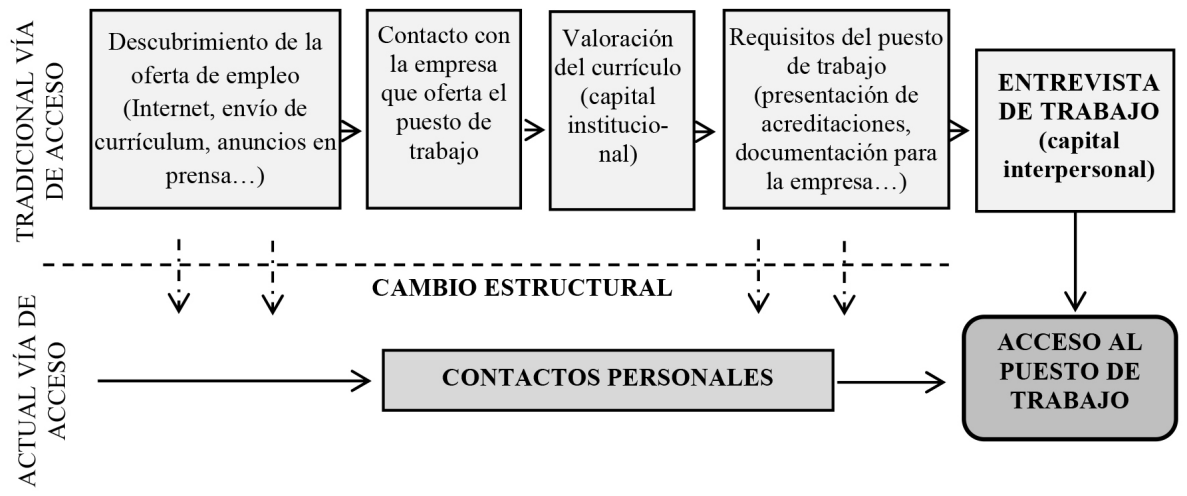

Fuente: Elaboración propia

Como se observa, a medida que las y los titulados avanzan por la vía tradicional de acceso al empleo se produce una valoración, cuantitativa y cualitativa, de la formación acreditada (capital institucional), así como de las competencias transversales (capital interpersonal). Pero, por medio de la actual vía de incorporación al mercado de trabajo, un egresado/a se insertaría laboralmente a través de la evaluación de su capital interpersonal, sin referencia expresa, en muchas ocasiones, a su capital institucional, lo que también señalan los estudios de la Fundación UniversidadEmpresa (2004), Escot y Fernández (2013) y Parellada (2014).

En estos términos, el desarrollo de competencias interpersonales como la capacidad crítica y autocrítica, el trabajo en equipo, la capacidad para trabajar en entornos interdisciplinares o la de comunicarse con expertos de otras áreas, son una importante llave que da acceso al mundo del trabajo (Lorenzo, 2013), principalmente si lo que se busca es la congruencia entre el funcionamiento del mercado y el modelo basado en competencias introducido por el EEES (González y Wagenaar, 2003), en un contexto caracterizado por la complejidad de esquemas perceptivos y la construcción de conocimientos compartidos (Santos, 2005). No obstante, se encuentran estudios que refieren desequilibrios por titulaciones en la adquisición de dichas competencias interpersonales, las cuales apenas tienen un desarrollo significativo en las ramas de artes, humanidades y ciencias (Ministerio de Educación, Cultura y Deporte, 2016).

Existe, por tanto, un reconocimiento explícito de que los contactos personales son una de las vías más útiles de incorporación a un puesto de trabajo (Alonso, Fernández, y Nyssen, 2008). Esto implica que el principio del mérito, visible a través de los logros académicos y del capital institucional, no sea considerado prioritario 
actualmente en los procesos de selección, siendo necesario favorecer el incremento del capital interpersonal de los estudiantes universitarios y promover el desarrollo de competencias esenciales para su inserción profesional, apoyándonos para ello en la gestión del conocimiento.

\section{LA GESTIÓN DEL CONOCIMIENTO EN LA INSERCIÓN LABORAL DE LAS Y LOS GRADUADOS UNIVERSITARIOS}

Se entiende por gestión del conocimiento el proceso sistemático y dinámico de detectar, seleccionar, organizar, procesar, presentar y utilizar la información por parte de las personas, con el objetivo de explotar los recursos de conocimiento basados en su capital intelectual (Cantón y Ferrero, 2016).

El primer paso para implementar un proceso de gestión del conocimiento es lograr un equilibrio entre lo subjetivo (tácito) y lo objetivo (explícito), tal y como señala Polanyi (2009). Este equilibrio se consigue cuando el conocimiento personal, estructurado en red, alimenta a las organizaciones, las cuales a su vez retroalimentan a la red, proveyendo nuevo aprendizaje para los individuos (Ayuste, Gross, y Valdivielso, 2012).

Este desarrollo cíclico se corresponde con la dimensión epistemológica de creación de conocimiento (Nonaka y Takeuchi, 1995) o interacción entre el conocimiento explícito y el tácito, de individuos y organizaciones, que facilita la reconversión del conocimiento a través de procesos de socialización, exteriorización, combinación e interiorización. Por medio de estos procesos el conocimiento es enunciado y ampliado, desde el nivel individual a los niveles grupal, organizacional e interorganizacional, alcanzando la dimensión ontológica en el proceso de creación de conocimiento.

Este proceso permite identificar el conocimiento previo que poseen personas y organizaciones, para crear nuevo conocimiento que cubra las necesidades descubiertas (Vargas y Moreno, 2005). Bajo este supuesto, se hace necesario transformar los objetivos educativos de las instituciones universitarias y orientarlos más a la construcción personal del conocimiento que a la mera adquisición del mismo; favoreciendo la discriminación inteligente para seleccionar y filtrar la información más relevante, la creatividad para convivir con la incertidumbre, la confianza en las posibilidades de aprendizaje de cada persona, así como la consideración de las instituciones educativas como redes de conocimiento capaces de facilitar procesos de coproducción e interacción (Fernández-Salinero, 2012).

La gestión del conocimiento así entendida requiere desarrollar un capital intelectual o activo intangible que genere riqueza, compuesto por los siguientes elementos (Nonaka y Takeuchi, 1995):

- Capital humano: valor del conocimiento creado en las personas.

- Capital estructural: valor del conocimiento creado en la organización. 
- Capital relacional: valor del conocimiento creado por la organización o la persona en relación con su entorno.

A los que se añaden en este trabajo:

- Capital interpersonal: valor de las redes de contactos de las y los egresados para acceder a un empleo y sus capacidades para gestionar y aumentar dichas redes.

- Capital institucional: valor del título acreditativo y representativo del capital incorporado.

Estos dos últimos pueden ser considerados como los nuevos elementos de la gestión del conocimiento en el contexto de la educación superior. El primero reuniría parte del capital humano y relacional, conformándose lo que Andreu y Baiget (2016) denominan "conocimiento idiosincrásico»; y el segundo se apoyaría en el capital estructural o conocimiento de uso general, según los autores señalados. Ambos tipos de capital, para que se desarrollen con eficacia, deben favorecer la creación de un sistema de externalización (intercambio de conocimientos y experiencias), buscando tanto el beneficio económico como el social o cultural (Fiol y Lyles, 1985).

Desde esta perspectiva, se pasa de un enfoque tecnológico o funcionalista de la gestión del conocimiento, que considera a ese conocimiento meramente como un activo, a uno más social e interpretativo, que lo identifica como experiencia humana y práctica social (Andreu y Baiget, 2016). En este sentido, resulta esencial promover un proceso de gestión que parta de la extracción del conocimiento potencialmente útil para dar respuesta a determinadas necesidades (Bayón, 2002), con la finalidad de convertirlo en un producto tangible (Quinn, Anderson, y Finkelstein, 1998). Pero, ¿cómo identificar el conocimiento útil? Siguiendo el modelo de Rivero (2002), en el caso de que sea fácilmente accesible, se selecciona el más adecuado para realizar las tareas; en el caso de que no sea accesible se identifica para detectar posibles mejoras y, en el caso de que sea accesible pero claramente mejorable, se define el modo de implantar las mejoras.

Por tanto, el desarrollo de la presente propuesta se basa en un ciclo de tres fases que se apoyan en el modelo de Rivero (2002) y se explicitan en el Gráfico 2. 
GRÁFICO 2

Fases de identificación, análisis y gestión del conocimiento

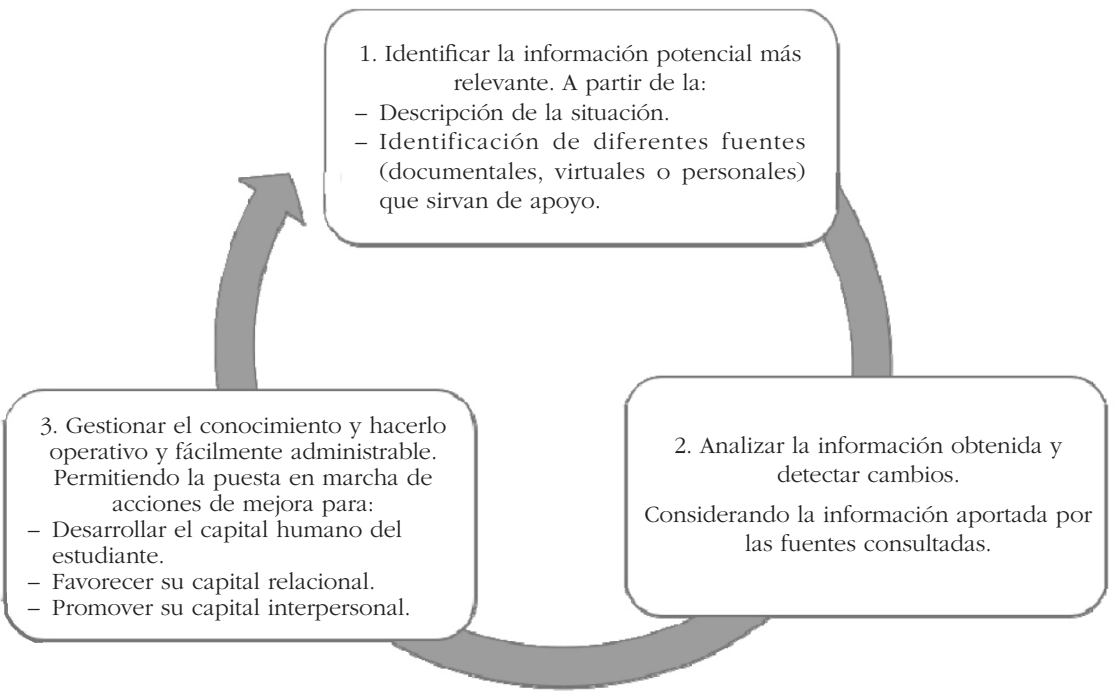

Fuente: Elaboración propia

Este proceso cíclico permite plantear propuestas centradas en el uso de la gestión del conocimiento. A este respecto, considerando el cambio que se está produciendo en el nivel de utilidad/efectividad de los recursos de intermediación laboral existentes y la prevalencia del factor "contactos» como principal vía de acceso — de la que no todos los graduados y graduadas pueden hacer uso-, se plantean tres líneas estratégicas de actuación:

- El conocimiento tácito (personal) debe convertirse en explícito (comunicable) y ha de llegar de nuevo al estudiante como conocimiento tácito enriquecido. Para ello, la educación superior debe promover la adquisición y desarrollo de competencias profesionales de carácter transversal, relacionadas con la identificación y utilización de información realista sobre el mercado laboral en su conjunto (Bridgstock, 2009), generando «trayectorias de aprendizaje» en los estudiantes, apoyadas en propuestas formativas online (MOOCS por ejemplo) o en otras presenciales y más clásicas como las derivadas de asignaturas transversales, ofertadas por algunas universidades españolas (caso de la Universidad Complutense de Madrid) como formación complementaria relacionada con temas de inserción laboral (Andreu y Baiget, 2016). Promoviéndose, con todo ello, la integración de conocimientos internos y externos, lo que aportará una ventaja competitiva a los estudiantes. 
- Es necesario vincular la universidad a colegios profesionales, asociaciones de ex-alumnos/as y organizaciones juveniles, a través de la creación de plataformas electrónicas conjuntas o "portales de conocimiento», mediante los cuales el alumnado tenga acceso a contenido personalizado y a una herramienta que ayude a crear entornos colaborativos (Andreu y Baijet, 2016). La participación de los jóvenes en dichos portales contribuye a la adquisición de un conocimiento real de las posibilidades profesionales de cada titulación en el mercado de trabajo y al desarrollo de su capital interpersonal (Souto-Otero, 2016).

- Crear una red de contactos sólida que los graduados y graduadas puedan utilizar una vez concluyan sus estudios se ha convertido en un desafío para las instituciones universitarias, por dos razones (Jackson, 2011). Primero, a causa del papel central que desempeña este recurso en la difusión de las salidas profesionales ligadas a cada titulación. Y segundo, porque la estructura de las redes de contactos tiene importantes implicaciones en la inversión en capital humano. Dichas redes pueden conformarse como "directorios", que contengan información, física o virtual, de las organizaciones del Prácticum, de los foros y ferias de empleo, de los encuentros con ex-estudiantes, de las sesiones de salidas profesionales y de las medidas de emprendimiento; convirtiéndose en una herramienta útil para mitigar las desigualdades sociales de los estudiantes universitarios y para favorecer el desarrollo de comunidades de prácticas que permitan intercambiar aprendizajes basados en la reflexión compartida sobre experiencias concretas.

Es así como la gestión del conocimiento se transforma en una herramienta adecuada para atender las nuevas necesidades de la educación superior (Encina, 2008), consistentes en la creación de un entorno donde la información y el conocimiento disponibles sean accesibles, se valoren, compartan, gestionen y usen, eficaz y eficientemente, para mejorar la toma de decisiones. Ello justifica nuestra propuesta centrada en la gestión del conocimiento como elemento facilitador de la transición al empleo de graduados y graduadas, al influir de forma directa sobre su capital. Por tanto, se convierte en un exponente relevante en la sociología de Bourdieu (2000; 2007), pues además de intervenir en la construcción de ese capital, analiza su valor, al tiempo que estudia las oportunidades ofrecidas a las y los estudiantes y enfatiza el compromiso y responsabilidad social de la universidad a la hora de identificar redes de colaboración.

Lo anterior implica un importante reto, que obliga a la educación superior a asumir la tarea de diseñar y poner en marcha las herramientas oportunas para gestionar el propio conocimiento, no solo facilitando su acceso, sino también estableciendo los canales necesarios para participar en su construcción. Todo ello 
PERSONALES. UNA PROPUESTA DESDE LA GESTIÓN DEL CONOCIMIENTO

permitirá que, tanto las y los graduados como determinados grupos de interés, vinculen su proceso formativo y profesional.

Por más que la investigación se haya centrado en la situación laboral de graduados y graduadas, es igualmente importante que la institución universitaria se ocupe de la recopilación de información relativa a la situación del mercado de trabajo, ofertas de empleo, prácticas en empresas, becas de trabajo y otras noticias de interés. Dicho de otro modo, la universidad también ha de funcionar como capital social mediador.

El nuevo modelo de educación superior supone situar el sistema universitario a la altura de una sociedad globalizada y en plena internacionalización. Por esta razón, resulta imprescindible identificar aquellas prácticas que han demostrado incidir en la empleabilidad de universitarios y universitarias de otras latitudes, analizando su posible aplicabilidad, tal y como advierten los distintos informes internacionales referenciados en este trabajo.

En definitiva, y siguiendo a Passaillaigue y Estrada (2016), las universidades han sido siempre instituciones centradas en el conocimiento y su gestión, por lo tanto, constituye una oportunidad y una exigencia, en su responsabilidad formadora, la preparación de escenarios para aplicar los métodos y técnicas apropiados al contexto y a los objetivos de las organizaciones laborales.

\section{Conclusiones}

En la actualidad, la configuración de un capital basado en las relaciones (contactos personales de distinto tipo) y las competencias interpersonales se está convirtiendo en un recurso de potencial empleabilidad, lo que está repercutiendo en la pérdida de valor del capital institucional de las y los egresados, esto es, de su formación académica acreditada, como vía de acceso al empleo. Dicha empleabilidad debe ser entendida como la competencia que tiene un individuo para integrarse en el mercado de trabajo, es decir, es el capital transformable y transferible que resulta útil para la inserción laboral (García-Blanco y Cárdenas-Sempértegui, 2018).

Por otra parte, el reciente y paulatino incremento de la utilidad socio-económica del capital interpersonal supone un cambio en relación a la búsqueda de empleo y pone de manifiesto la necesidad de que las instituciones de educación superior conozcan la situación del mercado de trabajo, ofreciendo a los futuros trabajadores competencias interpersonales que les permitan acceder al empleo, a través de la optimización de sus redes de contactos. A este respecto, informes internacionales como los procedentes de NACE en Estados Unidos y de CHEERS, REFLEX y PROFLEX en la Unión Europea y en Latinoamérica, sirven de precedente a esta investigación al analizar la influencia de las competencias interpersonales en la inserción laboral de las y los graduados universitarios.

La situación internacional se plantea como el punto de partida para conocer la de nuestro país. Para ello, con el objeto de identificar las condiciones que definen el 
acceso de las y los titulados universitarios españoles al mercado de trabajo, se lleva a cabo una precisa revisión documental sistemática y planificada, bajo el paraguas de la teoría fundamentada, metodología cualitativa de naturaleza exploratoria que permite identificar la trayectoria de búsqueda de empleo de egresados y egresadas, desde el año 2000 hasta el 2018, en las diferentes Comunidades Autónomas que conforman nuestro país, y que aporta una idea clara de la superioridad del cambio de enfoque sobre la singularidad territorial. Se descubre a partir de este análisis, una paulatina transformación, desde una vía de acceso tradicional más pendiente del capital institucional de las y los graduados, a una que se va asentando poco a poco en el mercado laboral y que apuesta por el capital interpersonal de manera prioritaria. Este proceso de cambio se plantea en este trabajo como el inicio de una línea de investigación dirigida a generar, en un futuro, una teoría pedagógica que sustente el nacimiento de un nuevo paradigma.

En este sentido, se constata la necesidad de que la universidad organice una agenda formativa más amplia y rica en contenidos relacionados con las competencias interpersonales. Competencias como la capacidad crítica y autocrítica, el trabajo en equipo, las habilidades socio-relacionales, la capacidad para trabajar interdisciplinarmente o la de comunicarse con expertos de otras áreas resultan decisivas para incrementar el capital interpersonal del alumnado y capacitarlo para la búsqueda de empleo. Este capital interpersonal, junto con el humano, estructural y relacional, dan un nuevo sentido al capital intelectual que subyace tras la gestión del conocimiento, la cual genera un proceso cíclico que se apoya en la información contextualizada como herramienta para producir un conocimiento útil en el estudiante, favoreciendo la optimización de sus competencias interpersonales y mostrando a la universidad el camino a seguir para incrementar dicho capital. Todo ello, superando el enfoque tecnológico o funcionalista de la gestión del conocimiento, que considera a ese conocimiento meramente como un activo, para promover uno más social e interpretativo, que favorezca el desarrollo de las trayectorias de aprendizaje de las y los estudiantes, la creación de portales de conocimiento, concebidos como entornos colaborativos, y la puesta en marcha de directorios que contengan información sobre el mercado laboral.

En definitiva, este trabajo ha permitido descubrir la importancia que tienen las lógicas de búsqueda de empleo para el ámbito académico, el cual debe estar en una constante tensión con el mercado laboral para facilitar la incorporación de las y los egresados al mismo. En prospectiva, una investigación más amplia podría aportar información sobre los efectos de la desigualdad social en las conexiones personales o sobre las consecuencias de las diferentes condiciones de inserción de las y los graduados en función de las ramas de conocimiento. Dos temas que, a pesar de su interés, todavía no han sido abordados profundamente por la investigación educativa en España. 
CAROLINA FERNÁNDEZ-SALINERO DE MIGUEL Y JESÚS GARCÍA-ÁLVAREZ LA INSERCIÓN LABORAL DE GRADUADOS Y GRADUADAS A TRAVÉS DE LOS CONTACTOS PERSONALES. UNA PROPUESTA DESDE LA GESTIÓN DEL CONOCIMIENTO

\section{REFERENCIAS BIBLIOGRÁFICAS}

Agència per a la Qualitat del Sistema Universitari de Catalunya. (2017). La inserció laboral de les graduats i graduades de les universitats catalanes. Barcelona: Autor.

Alonso, L. E., Fernández, C. J. y Nyssen, J. M. (2008). El debate sobre las competencias. Una investigación cualitativa en torno a la educación superior y el mercado de trabajo en España. Madrid: ANECA.

Andreu, R. y Baiget, J. (2016). Gestión del conocimiento y competitividad. Pamplona: Eunsa.

Axencia para a Calidade do Sistema Universitario de Galicia. (2004). Proxecto de inserción laboral dos titulados polo sistema universitario de Galicia 1996-2001. Santiago de Compostela: Autor.

Axencia para a Calidade do Sistema Universitario de Galicia. (2016). Estudo da inserción laboral dos titulados no Sistema Universitario de Galicia 2011-2012. Santiago de Compostela: Autor.

Ayuste, A., Gross, B. y Valdivielso, S. (2012). Sociedad del conocimiento. Perspectiva pedagógica. En L. García (Ed.), Sociedad del conocimiento y educación (pp. 17-40). Madrid: UNED.

Bayón, F. (2002). Organizaciones y Recursos Humanos. Madrid: Síntesis.

Beech, S. (2015). International student mobility: the role of social networks, Social \& Cultural Geography, 16(3), 332-350. https://doi.org/10.1080/14649365.2014.983961

Bisquerra, R. (Coord.). (2009). Metodología de la investigación educativa. Madrid: La Muralla.

Boden, R. y Nedeva, M. (2010). Employing discourse: universities and graduate 'employability', Journal of Education Policy, 25(1), 37-54. https://doi.org/10.1080/02680930903349489

Bourdieu, P. (2000). Poder, derecho y clases sociales. Bilbao: Desclée de Brouwer.

Bourdieu, P. (2007). El sentido práctico. Madrid: Siglo XXI.

Boyano, J. (2011). Estudio sobre la oferta y la demanda del mercado de trabajo de alta cualificación en Castilla y León, en el marco del Espacio Europeo de Educación Superior. Valladolid: Servicio Público de Empleo de Castilla y León.

Bridgstock, R. (2009). The graduate attributes we've overlooked: enhancing graduate employability through career management skills. Higher Education Research \& Development, 28(1), 31-44. https://doi.org/10.1080/07294360802444347

Burt, R. (1995). Structural Holes: The Social Structure of Competition. Cambridge: Harvard University Press.

Cabrera, A. F., Weerts D. J. y Zulick B. J. W. (2003). Encuestas a egresados: Tres Fundamentos Conceptuales en el Seguimiento de Egresados Universitarios. En J. Vidal García (Coord.), Métodos de análisis de la inserción laboral de los universitarios (pp. 55-80). México: Universidad de Nuevo León.

Cantero, M. P. (2012). Competencias socio-emocionales en la inserción laboral del egresado universitario. Alicante: Universidad de Alicante.

Cantón, I. y Ferrero, E. (2016). La gestión del conocimiento en revistas de educación. Educar, 52(2), 401-422. https://doi.org/10.5565/rev/educar.757

Cardenal, M. E. (2010). La formación universitaria en la ULPGC y el empleo: Estrategias de inserción laboral. Las Palmas de Gran Canaria: Observatorio de Empleo de la Universidad de Las Palmas de Gran Canaria. https://doi.org/10.4067/S0718-50062010000600004 
CAROLINA FERNÁNDEZ-SALINERO DE MIGUEL Y JESÚS GARCÍA-ÁLVAREZ LA INSERCIÓN LABORAL DE GRADUADOS Y GRADUADAS A TRAVÉS DE LOS CONTACTOS PERSONALES. UNA PROPUESTA DESDE LA GESTIÓN DEL CONOCIMIENTO

Carot, J. M., Conchado, A., Mora, J. G. y Vila, L. (2011). La opinión de los graduados europeos sobre la universidad cinco años después de haber finalizado sus estudios. Revista de Sociología, 96(4), 1269-1285. https://doi.org/10.5565/rev/papers/v96n4.181

Carrascosa, J. R. y Molero, D. (2010). Ocupación laboral y formación complementaria de los titulados universitarios. Bordón, 62(1), 109-122. https://goo.gl/rsFB8B

Confederación de Empresarios de Navarra. (2012). Competencias Profesionales para el siglo XXI. Confederación de Empresarios de Navarra. Pamplona: Observatorio Navarro de Empleo.

Davenport, T. H. y Prusak, L. (1998). Working Knowledge: How Organizations Manage What They Know. Boston, USA: Harvard Business School Press.

De Esteban, M. y Sancho, M. A. (Dir.). (2017). Las competencias de los universitarios y las demandas del mercado laboral. Madrid: Fundación Europea Sociedad y Educación.

Del-Arco, I. y Enciso, P. (2011). Valoración de las competencias instrumentales de los titulados universitarios: estudio comparativo. Bordón, 63(3), 91-105. https://goo.gl/qHTCGC

DuBrin, A. J. (1997). Human Relations. Interpersonal, Job-Oriented Skills. New Jersey, USA: Prentice Hall.

Encina, A. (2008). Gestión del conocimiento en la educación universitaria. Población y Desarrollo, 35, 79-93. https://goo.gl/sd5n2Z

Escot, L. y Fernández, J. A. (Coords.). (2013). Panorama Laboral 2013. Encuesta sobre métodos de búsqueda de empleo en la Comunidad de Madrid. Madrid: Consejería de Empleo, Turismo y Cultura de la Comunidad de Madrid.

Fernández-Salinero, C. (2012). Cómo gestionar el nuevo conocimiento pedagógico. En L. García (Ed.), Sociedad del conocimiento y educación (pp. 61-66). Madrid: UNED.

Fernández-Salinero, C. y De la Riva, B. (2014). Entrepreneurial Mentality and Cultures of Entrepreneurship. Procedia-Social and Behavioral Sciences, 139(22), 137-143. https:// doi.org/10.1016/j.sbspro.2014.08.044

Fiol, M. C. y Lyles, M. A. (1985). Organizational Learning. Academy of Management Review, 10(4), 803-813. https://doi.org/10.5465/amr.1985.4279103

Flap, H. y Boxman, E. (2000). Getting started: The influence of social capital on the start of the occupational career. En N. Lin, K. Cook y R. Burt (Eds.), Social Capital: Theory and Research (pp. 159-181). New York, NY: Aldine de Gruyter. https://doi. org/10.4324/9781315129457-7

Fondo Monetario Internacional. (2016). La respuesta del FMI a la crisis financiera mundial. Recuperado de https://goo.gl/tFwQhi (Consultado el 02/11/2018).

Freire, M. J. (2009). La inserción laboral de los graduados de la Universidad de A Coruña 2006/2007. A Coruña: Observatorio Ocupacional de la Universidad de A Coruña.

Freire, M. J. (2012). Informe de Inserción Laboral de los Graduados de la UDC. Curso 2009/2010. A Coruña: Observatorio Ocupacional de la Universidad de A Coruña.

Fundación Universidad-Empresa. (2004). Las demandas sociales y su influencia en la planificación de las titulaciones en España en el marco del proceso de convergencia europea en educación superior. Madrid: Autor.

Fundación Universidad-Sociedad. (2010). Análisis de las fortalezas y debilidades de los titulados/as universitarios/as en la búsqueda de empleo. 2010. Pamplona: Servicio Navarro de Empleo. 

PERSONALES. UNA PROPUESTA DESDE LA GESTIÓN DEL CONOCIMIENTO

Fundación Universidad Carlos III. (2009). XIII Estudio de inserción profesional de los titulados de la Universidad Carlos III de Madrid. Promoción 2007. Madrid: Servicio de Orientación y Planificación Profesional.

Fundación Universidad Carlos III. (2018). XXII Estudio de Inserción Profesional de los Titulados de la Universidad Carlos III de Madrid. Promoción 2016. Madrid: Servicio de Orientación y Planificación Profesional.

García, A. J. (Coord.). (2016). Competencias sociales en las relaciones interpersonales y grupales. Madrid: Pirámide.

García-Blanco, M. y Cárdenas-Sempértegui, E. B. (2018). La inserción laboral en la Educación Superior. La perspectiva latinoamericana. Educación XX1, 21(2), 323-347. https://doi. org/10.5944/educxx1.16209

García-Gutiérrez, J. (2014). ¿Por qué lo llaman educación cuando quieren decir (...) empleabilidad? A propósito del concepto de utilidad en educación. Procedia-Social and Behavioral Sciences, 139, 102-109. https://doi.org/10.1016/j.sbspro.2014.08.034

García-Montalvo, J. y Ginés-Mora, J. (2000). El mercado laboral de los titulados superiores en Europa y en España. Papeles de Economía Española, 86, 111-127. https://goo.gl/Cfnhtu

García-Montalvo, J. y Peiró, J. M. (2009). Análisis de la sobrecualificación y la flexibilidad laboral. Observatorio de inserción laboral de los jóvenes 2008. Valencia: Fundación Bancaja.

García-Montalvo, J. y Peiró, J. M. (2011). Crisis económica e inserción laboral de los jóvenes: Resultados del Observatorio de Inserción Laboral de los Jóvenes. Valencia: Instituto Valenciano de Investigaciones Económicas.

García-Palma, M. B. y Martínez, A. (2014). La inserción laboral de los titulados de la Universidad de Murcia. Informe 2014. Promociones 09/10 y 10/11. Murcia: Servicio de Orientación y Empleo.

García-Valdecasas, J. I. (2014). El impacto de la estructura de las redes sociales sobre el acceso de los individuos al mercado laboral. Revista Internacional de Sociología, 72(2), 303-321. https://doi.org/10.3989/ris.2012.09.13

Gil, P. (2011). Empleadores y Titulados UPV. Estudio de Empleabilidad de Titulados de la Universitat Politècnica de València. Valencia: Universidad Politécnica de Valencia.

González-Santos, J. M., Ratia, O. y Yagüe, M. A. (Coords.). (2011). Estudio de Inserción Laboral. Año 2011. Universidad de Zaragoza. Zaragoza: Observatorio de Empleo Universitario de la Universidad de Zaragoza.

González, J. y Wagenaar, R. (2003). Tuning educational structures in Europe: Informe final Fase Uno. Bilbao: Universidad de Deusto.

Harvey, W. (2008). Strong or weak ties? British and Indian expatriate scientists finding jobs in Boston, Global Networks, 8(4), 453-473. https://doi.org/10.1111/j.1471-0374.2008.00234.x

Ichijo, K. y Nonaka, I. (2006). Knowledge creation and management: New challenges for managers. New York: Oxford University Press.

Instituto Nacional de Estadística. (2010). Estadística sobre titulados universitarios según los medios utilizados para encontrar trabajo por sexo, Comunidad Autónoma de su universidad y ámbito de estudio. Recuperado de https://goo.gl/Gr3PSN (Consultado el 18/12/2018). 
CAROLINA FERNÁNDEZ-SALINERO DE MIGUEL Y JESÚS GARCÍA-ÁLVAREZ LA INSERCIÓN LABORAL DE GRADUADOS Y GRADUADAS A TRAVÉS DE LOS CONTACTOS PERSONALES. UNA PROPUESTA DESDE LA GESTIÓN DEL CONOCIMIENTO

Instituto Nacional de Estadística. (2016). Encuesta de inserción laboral de titulados universitarios 2014. Recuperado de https://goo.gl/G4jt5U (Consultado el 04/01/2019).

Instituto Nacional de Estadística. (2018). Resultados nacionales. Tasas de paro por nivel de formación alcanzado, sexo y grupo de edad. Recuperado de https://goo.gl/jtaFFx (Consultado el 16/12/2018).

Instituto de la Mujer. (2008). Acceso al mercado laboral de las tituladas superiores en España: empleabilidad y cualificación. Madrid: Autor.

Jackson, M. O. (2011). An Overview of Social Networks and Economic Applications. En J. Benhabib, A. Bisin y M. O. Jackson (Eds.), Handbook of Social Economics (pp. 511-585). Amsterdam, Netherlands: North Holland. https://doi.org/10.1016/B978-0-444-531872.00012-7

Jover, G. (2016). Aprendizaje y pragmatismo universitario en la sociedad del conocimiento. En M.A. Santos (Ed.), Sociedad del conocimiento. Aprendizaje e Innovación en la Universidad (pp. 23-40). Madrid: Síntesis.

Lorences, J. (2005). Empleabilidad de los titulados de la Universidad de Oviedo. Avilés: Consejería de Economía y Administración Pública del Gobierno del Principado de Asturias.

Lorenzo, M. (2013). Pedagogía laboral y sociedad cosmopolita: formación y gestión de la incertidumbre. En M. A. Santos (Ed.), Cosmopolitismo y educación. Aprender y trabajar en un mundo sin fronteras (pp. 163-176). Valencia: Brief.

Mairata, M. J. (2008). La inserció laboral i la satisfacció dels graduats i graduades: indicadors clau de la qualitat de la formació que ofereix la Universitat de les Illes Balears. Anuari de l'Educació de les Illes Balears, 2008, 168-183. https://goo.gl/kh4gLa

Michavila, F., Martínez, J. M., Martín-González, M., García-Peñalvo, F. J. y Cruz-Benito, J. (2016). Barómetro de empleabilidad y empleo de los universitarios en España 2015. Primer informe de resultados. Madrid: Observatorio de Empleabilidad y Empleo Universitarios.

Ministerio de Educación, Cultura y Deporte. (2015). Inserción laboral de los egresados universitarios. La perspectiva de la afiliación a la Seguridad Social. Primer Informe. Madrid: Autor.

Ministerio de Educación, Cultura y Deporte. (2016). Datos y cifras del sistema universitario español. Curso 2015-2016. Madrid: Autor.

Mora, J. G., Carot, J. M. y Conchado, A. (Eds.). (2010). PROFLEX. El Profesional Flexible en la Sociedad del Conocimiento. Valencia: Goyza.

Neira, I., Portela, M., Cancelo, M. T. y Calvo, N. (2013). Capital social y humano como determinantes del emprendimiento en las regiones españolas. Investigaciones regionales: Journal of Regional Research, 26, 115-139. https://goo.gl/4oeGhj

Nonaka, I. y Takeuchi, H. (1995). The Knowledge-creating Company. New York: Oxford University Press.

Observatorio de Inserción Laboral y Tendencias Profesionales Emergentes de la Universidad de la Rioja. (2010). Estudio de inserción laboral de los titulados. Curso 2005/06. Logroño: Autor.

Observatorio de Empleo de la Universidad Autónoma de Madrid. (2010). La Inserción Laboral de los Titulados de la Universidad Autónoma de Madrid del curso 2007/2008. Madrid: Autor.

Observatorio de Empleo de la Universidad Autónoma de Madrid. (2016). La Inserción Laboral de los Titulados de la Universidad Autónoma de Madrid del curso 2013/2014. Madrid: Autor. 

PERSONALES. UNA PROPUESTA DESDE LA GESTIÓN DEL CONOCIMIENTO

Observatorio de Empleo Universitario de la Universidad de Zaragoza. (2006). Estudio de Inserción Laboral. Universidad de Zaragoza. Año 2006. Zaragoza: Autor.

Observatorio del Mercado de Trabajo-LANBIDE. (2010). Incorporación a la Vida Activa de personas tituladas universitarias en la UPV-EHU. Promoción 2006. Vitoria-Gasteiz: Autor.

Observatorio del Mercado de Trabajo-LANBIDE. (2017). Estudio de Incorporación a la Vida Laboral. Inserción Laboral Diciembre 2016. Vitoria-Gasteiz: Autor.

Observatorio Ocupacional de la Universitat Jaume I. (2003). La inserción laboral de los titulados de la Universitat Jaume I. Promociones de 1998, 1999 y 2000. Castellón: Autor.

Osuna, E., Sánchez, J. y López, A. (Dirs.). (2006). La inserción laboral de los titulados de la Universidad de Murcia. Titulados en los cursos académicos 2001/2002, 2002/2003 y 2003/2004. Murcia: Unidad para la Calidad de la Universidad de Murcia.

Parellada, M. (Dir.). (2014). Informe CYD 2014. La contribución de las universidades españolas al desarrollo. Barcelona: Fundación Conocimiento y Desarrollo.

Passaillaigue, R. y Estrada, V. (2016). La gestión del conocimiento y el aprendizaje organizacional en instituciones de educación superior. GECONTEC: Revista Internacional de Gestión del Conocimiento y la Tecnología, 4(2), 35-43. https://goo.gl/hcKGDr

Pérez, C., Vicente, F. y Cubo, S. (2008). Inserción sociolaboral de universitarios: aspectos psicosociales. International Journal of Developmental and Educational Psychology, 2(1), 349-364. https://goo.gl/QEqKD1

Pin, J. R., Apascaritei, P., Susaeta, L. y Gallifa, A. (2013). Objetivo: Reducir el desempleo juvenil en España. ¿Qué tienen que hacer Administración, empresas, educación y jóvenes? Madrid: IESE-Citi Foundation.

Pineda, P., Ciraso, A. y Armijos, M. (2018). Competencias para la empleabilidad de los titulados en Pedagogía, Psicología y Psicopedagogía: un estudio comparativo entre empleadores y titulados. Revista Española de Pedagogía, 76(270), 313-333. https://doi.org/10.22550/ REP76-2-2018-06

Polanyi, M. (2009). The Tacit Dimension. New York, USA: Doubleday.

Quinn, J. B., Anderson, P. y Finkelstein, S. (1998). Managing professional intellect: making the most of the best. Harvard Business Review, 74(2), 71-80. https://doi.org/10.1016/ B978-0-7506-9850-4.50009-9

Rahona, M. (2006). ¿La posesión de un título universitario facilita el acceso de los jóvenes al primer empleo? Una aproximación para el caso español. Revista del Ministerio de Trabajo y Asuntos Sociales, 61, 105-121. https://goo.gl/a7cBRB

Ramezan, M. (2011). Intellectual capital and organizational organic structure in knowledge society: How are these concepts related? International Journal of Information Management, 31(1), 88-95. https://doi.org/10.1016/j.ijinfomgt.2010.10.004

Ramírez y., Santos, J. F. y Tejada, A. (2011). Intellectual capital in Spanish public universities: stakeholders' information needs, Journal of Intellectual Capital, 12(3), 356-376. https:// doi.org/10.1108/14691931111154689

Rivero, S. (2002). Claves y pautas para comprender e implantar la gestión del conocimiento. Vizcaya: Socintec. 
CAROLINA FERNÁNDEZ-SALINERO DE MIGUEL Y JESÚS GARCÍA-ÁLVAREZ LA INSERCIÓN LABORAL DE GRADUADOS Y GRADUADAS A TRAVÉS DE LOS CONTACTOS PERSONALES. UNA PROPUESTA DESDE LA GESTIÓN DEL CONOCIMIENTO

Rodríguez, S. (2003). Educació Superior i Treball a Catalunya. Estudi de la inserció laboral dels graduats de les universitats públiques catalanes. Barcelona: Agència per a la Qualitat del Sistema Universitari de Catalunya.

Santos, M. A. (2005). La Universidad ante el proceso de convergencia europea: un desafío de calidad para la Unión. Revista Española de Pedagogía, 230, 5-16. https://goo.gl/9SHaCo

Servicio Integrado de Empleo de la Universidad Politécnica de Valencia. (2009). La inserción laboral de los Titulados de la Universidad Politécnica de Valencia. Titulados curso académico 2006/2007. Valencia: Servicio Integrado de Empleo.

Souto-Otero, M. (2016). Young people's views of the outcomes of non-formal education in youth organisations: its effects on human, social and psychological capital, employability and employment. Journal of Youth Studies, 19(7), 938-956. https://doi.org/10.1080/13 676261.2015 .1123234

Subires, M. P. y Olmedo, S. (2013). Universidad, sociedad y networking: perspectivas ante el uso de las redes sociales de perfil académico profesional, Estudios sobre el Mensaje Periodístico, 19, 1037-1047. http://dx.doi.org/10.5209/rev_ESMP.2013.v19.42188

Teichler, U. (2003). Aspectos metodológicos de las encuestas a graduados Universitarios. En J. Vidal García (Coord.), Métodos de análisis de la inserción laboral de los universitarios (pp. 15-29). México: Universidad de Nuevo León.

Trinidad, G., Villalobos, R. M., Martín, M. J. y Panduro, J. F. (2009). Estudio de inserción laboral. Egresado de los cursos 2003-04, 2004-05 y 2005-06. Cáceres: Universidad de Extremadura.

Unidad de Calidad y Prospectiva de la Universidad de Comillas. (2007). Informe. Inserción Laboral de los graduados de la Promoción 2004-05. Madrid: Autor.

Unidad de Calidad y Prospectiva de la Universidad de Comillas. (2011). Informe. Inserción Laboral de los graduados de la Promoción 08-09. Madrid: Autor.

Universidad de Cádiz. (2005). Egresados de la UCA a los tres años de finalización de los estudios. Cádiz: Unidad de Evaluación y Calidad de la Universidad de Cádiz.

Universidad de Cantabria. (2015). Resultado del proyecto piloto de estudio de egresados de la Universidad de Cantabria. Curso 2012-2013. Santander: Autor.

Universidad de Castilla La Mancha. (2005). Estudios sobre Calidad e Inserción Laboral y Encuesta a Empleadores. Salamanca: Oficina de Evaluación de la Calidad de la Universidad de Castilla La Mancha-Centro de Información y Promoción del Empleo.

Universidad de Jaén. (2008). Estudio de la inserción laboral de los titulados de la Universidad de Jaén. Informe 2008. Jaén: Autor.

Universidad de Jaén. (2012). Estudio de la inserción laboral de los/as titulados/as de la Universidad de Jaén. Informe 2012. Jaén: Autor.

Universidad Politécnica de Madrid. (2009). Resultados de las encuestas de Junio 2008 a Octubre 2009 a los egresados recién titulados. Madrid: Autor.

Universidad Politécnica de Madrid. (2017). Inserción laboral Grados. Titulados en el curso 2015-2016. Madrid: Vicerrectorado de Calidad y Eficiencia/Observatorio Académico de la Universidad Politécnica de Madrid.

Valero, F. J. (2003). Procesos de transición al mercado de trabajo: estrés y prácticas en empresa de la Universidad de Granada. Granada: Editorial de la Universidad de Granada. 
CAROLINA FERNÁNDEZ-SALINERO DE MIGUEL Y JESÚS GARCÍA-ÁLVAREZ LA INSERCIÓN LABORAL DE GRADUADOS Y GRADUADAS A TRAVÉS DE LOS CONTACTOS PERSONALES. UNA PROPUESTA DESDE LA GESTIÓN DEL CONOCIMIENTO

Valero, F. J. (2012). Estudio Demandas del Mercado Laboral a los Titulados Universitarios. Granada: Centro de Promoción de Empleo y Prácticas de la Universidad de Granada.

Vargas, A. y Moreno, M. J. (2005). La gestión del conocimiento en las organizaciones. Tourism E Management Studies, 1, 139-151. https://goo.gl/Favzdx

Vidal, J., López, R., Pérez, C. y Vieira, M. J. (2001). Graduados y empleo en la Universidad de León. León: Secretariado de Publicaciones de la Universidad de León.

Villalobos, R. M., Trinidad, G., Díaz, A. y Chamorro, A. (2014). Estudio de inserción laboral. Titulados del curso 2010-2011. Cáceres: Universidad de Extremadura.

Weller, J. (2007). La inserción laboral de los jóvenes: características, tensiones y desafíos. Revista de la CEPAL, 92, 61-82. https://doi.org/10.18356/427e4646-en 
